\title{
Semiosis, Information and Knowledge
}

\author{
Edwina Taborsky
}

Bishop's University, Lennoxville, Quebec J1M 1Z7, email: taborsky@primus.ca, Tel: Toronto: 416. 361.0898

\begin{abstract}
This paper understands knowledge and information to operate within a reality that is rendered dynamic by asymmetrical 'cuts' that ontologically divide reality into internal and external realms, and epistemologically divide experience into formal models and informal instances. Semiosis develops signs, understood as actions of knowledge and information, to mediate the asymmetry developed by these cuts.
\end{abstract}

Key words: asymmetry, external/internal realms, formal/informal codification

\section{INTRODUCTION}

This paper presents a critique of notions of information and knowledge found in the management literature and amongst proponents of 'knowledge management'. The definitions in this current usage are derived from technological sources, from lay interpretations presented in philosophical classics and from the management literature. They are buffeted about in language such as 'infodynamics', 'knowledge work', 'knowledge workers' and 'the knowledge based economy' and essentially reveal a perspective confused about its grounds and its direction ${ }^{28}$.

It is a tenet of this paper that a clear differentiation between knowledge and information and then, an analysis of their interaction, are vital components in the development of a rigorous science of information

${ }^{28}$ This article uses data on information in management gathered within two reports, based on research within a SSHRC Strategic Theme Grant on the Challenges and Opportunities of the Knowledge-Based Society: (i) Shields, R. and E. Taborsky 2001; and (ii) Shields, Ilcan, O'Connor, Taborsky 2001.

The original version of this chapter was revised: The copyright line was incorrect. This has been corrected. The Erratum to this chapter is available at DOI: 10.1007/978-0-387-35611-2_22 
systems. Information and knowledge are not identical and their relation is not a one-to-one process which sees both as 'things-in-themselves', with information possibly imagined as a 'billiard ball' and knowledge imagined as a 'collection of billiard balls'. These images are representative of the language of much of modern information technology. A mechanical inputoutput process is presumed in which each state of data, information or knowledge is presented as an object which is itself unchanged by the interactional process, but which, in a serial manner, leads to the next stage. This linear stimulus-response model takes the arrangement or processing of information to yield knowledge and the arrangement or processing of knowledge to yield action. Change is understood to result only from an external force with the power to disperse or collect and re-categorize those billiard balls. What new understandings would be required to break with the established focus on this mechanical manipulation of information - a model which is a staple of textbooks and the basis of multi-trillion dollar global information technology and management consulting industries? This paper will begin with an examination of the semiotic nature of both knowledge and information. It will examine the processing of information/knowledge as operations that take place within the external and internal zones of experiences of a population. Then, within each of these two areas, it will examine the processes of formal and informal codification, and finally, discuss a semiotic process that enables the adaptive evolution of a community in its nature as a knowledge-using and producing system.

We will begin with the basic concepts of semiotic realism, which can be understood, first, as a theory that acknowledges that information and knowledge are realities, which is to say, they are objective realities and not subjective phenomena. Second, information and knowledge are to be understood as ontological and epistemological realities developed by the dynamic transformation of energy to mass (Taborsky 2000, 2001a, c). What does this mean? Energy is the basic 'stuff' of our universe. According to the theory of relativity, there is no essential distinction between mass and energy, in the sense that the one is a version of the other. Within the analysis of this paper, their dynamic transformation is due to the establishment of an evolving network of semiotic measurement and codification, in varying degrees of complexity, which can be found within all processes of our universe, whether in the physico-chemical, biological or social realms. Our experience of a 'thing-in-itself' whether it is that 'billiard ball' or its symbolic image, is to be understood as energy that has been transformed from an inaccessible to an accessible state. It has become mass, which is to say, it is 'informed, interpreted energy'. It is now 'information', whether its information operates within a chemical molecule, a biological cell, a linguistic expression or a social system. We should not think of information 
and knowledge as phenomenal descriptions added by a conscious observer; we should consider them as the basic organized relations that form a 'thingin-itself. Our extrapolation of this organization, and explaining it within a semantic description, is a secondary semiotic step. Therefore, a basic theme in semiotic realism is its grounding in realism, a sense that information and knowledge operates in space and time, and furthermore, that these are dynamic processes, for "information is closely related to the idea of transformation, emergence of something new....[and can be defined as] a measure of quantity of form or as a measure of structural organization" (Weizsacker, in Fenzl 2000:192). The transformation of energy to informed mass is a primary semiotic process and operates within a series of increasingly complex steps:

a) The differentiation of energy into informed mass is achieved by means of semiosis or codification, which acts as a process of measurement of differentiations.

b) Energy is differentiated within a set of 'cuts', or actions of measurement, which separate energy into asymmetrical zones of activity. The first cut sets up an ontological reality of internal and external spatial territories. The external and internal levels operate within different modes of codification;

c) within both these internal and external spatial zones of codification, there will also be an epistemological cut that enables two different codifications: those that set up short term instantiations (information) and those that set up long term laws or formal memory (knowledge);

d) these codifications (internal and external; instantiations and memory) will also be understood to evolve in epistemological complexity within the three basic ontological realms, from the physico-chemical to the biological to the socioconceptual (Taborsky 1999, 2002). That is, we cannot understand information and knowledge as operative only within the human realm, which would confine semiotics to semiology (linguistics) but we extend its principles of measurement and codification, and the development of relational systemic processes, to all reality. We must, however, understand that the semiotic typologies of codification, such as iconic, indexical and symbolic, will not be found within all realms. For example, the physico-chemical realm operates primarily by iconic codes; the biological realm added the indexical semiosis to the iconic, and the symbolic code operates only within the human realm. 


\section{THE NATURE OF ENERGY AND DIFFERENT TYPES OF ENERGY}

The analysis in this paper uses a basic definition that energy is the basis of all abiotic and biotic ontology but that it exists only as codified or organized mass. We can consider the information/knowledge dynamics of an abiotic realm as a mechanical information system, and those of a biotic realm as an organic or human information system. This is not a reductionist view which sees reality as collections of atomic particles but is a dynamic analysis, which understands that this 'codified mass', whether it be existent in its organization as an electron field, a biological organism, a word, an ideology, a society, is an active process with mass moving into discrete forms, dissolving and reforming into other discrete forms. Codes, which are actions of measurement, are constraints, with the result that one demarcated or actualized energy is differentiated from other forms of energy. Therefore, a basic postulate is that energy cannot exist, in its pure state, as motion, as heat, as 'the force to do work' but can exist only within the restrictions and constraints of codification. Furthermore, energy that is codified should be understood in this constrained state not simply as 'matter', for matter does not exist as a pure isolate state, but should more accurately be understood as 'information' because this energy is, as constrained, in a relationship with other forms of mass and is then capable of informing on and about other forms of energy-as-matter, by relating its codes and organizational properties to these other forms of coded energy. This process of associative measurement in no way involves a deliberative or conscious interaction. Mind, the logical and communal action of measurement, operates to transform energy to mass or information but Mind is not necessarily human or conscious. Therefore "there is something in nature to which the human reason is analogous" (Peirce 1.315) and Mind "is not consciousness" for "consciousness is a special and not a universal accompaniment of mind" (Peirce 7.365-366). There is a need "for mentality to be 'ontologically fundamental"' (Penrose 1997:176). If one understands information as sensate matter to which has been added meaning in the form of organized 'situated' links (Davenport and Prusak 1998; Devlin 1999), then this meaning must itself be grounded within a formal and reasonably stable organisation. Mind should be understood, not merely within our common sense of an intentional and conscious agency, but as a logical, which is to say, as a formal process of organisation. The measurement that establishes the physical reality of a hydrogen atom as distinct from a helium atom, is a formal and mental action because this measurement operates within a collective general law rather than evanescent individual randomness, and this law of organisation governs all future dynamics of these atoms. That is, Mind should be understood as 
the formal laws of organisation of our universe. These laws are, in themselves, not a priori, not transcendental, not mechanical but are a dynamic process and co-evolve with the evolution of information and knowledge complexities of our universe (Taborsky 1999). The process of codification of energy transforming it from a symmetrical undifferentiated potency to differentiated singularities of mass/information, operating within asymmetry, is known as semiosis. Semiosis is not confined within language or human or biological consciousness but begins and evolves in complexity, from the lowest possible energy state.

\section{TWO ZONES OF CODIFICATION}

The most obvious result of the semiosic process of measurement and codification is the differentiation of the 'featureless' to the 'featured', which is to say, the differentiation of an incomprehensible symmetry of chaos into singular realities that can be physically and/or conceptually experienced. This codal transformation into discrete matter and concepts and their relations operates within an infrastructure made up of a series of increasingly complex cuts of energy that sets up this 'mass' of energy within asymmetrical zones of semiosic processes.

The most basic cut is ontological, the distinction between an instance of mass and its environment. This cut measures mass into zones of the external and the internal. This has been defined as 'the Heisenberg cut' (Matsuno 1999, Primas 1993, Atmanspacher 1994, 1999). This cut, with its distinction between an object and its environment, sets up a dualism that sees both the internal and the external as separate domains of codification, "forming a separating boundary between two phases, like the surface of a liquid" (Christiansen 2000:51), for "by creating a topological closure the membrane established an inside-outside asymmetry which must be an absolutely decisive step because it opens the door to the semiotic world of communication and function and thereby to the formation of an individualized context space or agency" (Hoffmeyer 2001:125; italics in original). This cut enables differentiation into singulars, operating as such by virtue of their separation from and their relations with, their environment and is the basis also of systems analysis, understood as the 'complex relation of such singular parts with wholes'.

Codification in the external zone ignores what is going on inside an entity and considers that entity only from the holistic separateness of an observer's stance. Measurements or interactions of mass in this zone refer only to their external properties, with their internal natures impenetrable except by a reductionist decomposition into parts. This is the mechanical exoperspective, 
a view familiar within both systems theory and organizational analysis. In contrast, the internal realm operates within an equally isolate codification but one that manages entirely within a closed endoperspective, a state "prior to object-subject bifurcation, in which the so-called external world becomes totally deprived of its ontological solidity" (Atmanspacher and Dalenoort 1994:1). Measurement and interactions of mass on this subjective level possess a basic uncertainty and amorphousness because they lack reference to an 'other' reality with the result that discrete and stable descriptions are impossible (See Matsuno \& Paton 2000; Matsuno 2001). However, despite their differences, we must assume that these two modes of codification, the external and internal, are entailed, with each supplying a vital component for the whole knowledge process.

A second cut, the epistemological, divides both the external and internal realms into "both facts and models" (Atmanspacher 1994:15, italics in original). This is the familiar body/mind distinction and has been described as 'the Cartesian cut' (Matsuno 1999, Atmanspacher 1994, 1999, Primas 1993). That is, within the internal and external modes of codification, we will have codifications that operate as discrete instantiations or what we can understand as singular 'facts' or 'information' and codifications that operate as a general formal model or what we can understand as a common 'hypothesis' or overall 'metatheory'. Both the external objective and the internal subjective zones must provide both these fixed constraints of communal normative codification which we will understand as 'mind', and also these flexible singular codifications which we will understand as 'body'. What we will further explore is that this epistemological cut measures this mind/body differentiation within two different codal types. The formal model will be encoded digitally while the informal instantiation will be encoded analogically. This differentiation of code, along with the basic differentiation into spatial zones, is another means to enable dynamics, understood as transformative interactions. These cuts, which set up asymmetry, establish an essential infrastructure for the robust processing of knowledge and information.

The pragmatic result of the ontological cut into internal and external zones of reality and the epistemological cut into realms of formal and informal experiences of that reality is a robust system that enables a dynamic production of new information and knowledge. Asymmetry is an acknowledgment of differentiation. Differences permit change, learning and adaptation. Our universe began in symmetry and very rapidly moved into asymmetry, with semiosis emerging as the means to 'measure' or conciliate these differences. Imagine a world that was completely symmetrical, with all its parts each like the other, each blended with the other, much like a bowl of jello. Differentiation is the basis of interactions and of all our attempts to 
mediate our differences and in so doing, enables our cosmos to establish complex organisms such as societies. How does this complex semiosis , which I maintain is an essential operative process within the physicochemical, the biological and the socioconceptual realms (Taborsky 1999) operate as an information-generating system? Let us consider the intricacies of semiosic codification.

\section{THE SEMIOSIC CATEGORIES}

Differences in codification enable mass to exist as differentiated singulars whether material and/or conceptual, and to have different types of relations with other mass. For example, a particular code interaction sets up an amorphous gas or a vague idea and the relations that are possible within this gas-form or idea-form are different from those within forms which are more clearly differentiated within their ontological boundaries. Another codification will set up mass as highly charged, attracting other mass to it, like a distinct electron field or a vibrant state of emotional excitation. Another type of codification will, as in a rock or a fundamentalist social ideology, freeze and inhibit relations. The nature of semiosic codification is too complex to be dealt with in this paper (but see Taborsky 1999, 2000, 2001). Therefore, I will introduce only the three basic modes or categories of semiosic codification as outlined within Peircean semiotics. These are a Firstness of possibility, a Secondness of individuality and a Thirdness of normative habits of the community. These are only the basic modes; in the interpretive actualization of energy to mass, these modes will readily combine and become more complex. A key factor to remember is that the vehicle of this interactive process is the triadic sign; that is, the sign is not a 'thing' but a process, which is to say, it is an action of codification, and as such an action, it operates within three nodal points. As Peirce defined the sign, it is "anything which determines something else (its interpretant) to refer to an object to which itself refers (its object) in the same way, the interpretant becoming in turn a sign, and so on ad infinitum" (Peirce 2.303).

Firstness is feeling, quality, chance, immediacy, "an instance of that kind of consciousness which involves no analysis, comparison or any process whatsoever, nor consists in whole or in part of any act by which one stretch of consciousness is distinguished from another" (Peirce 1.306). Any experience that is codified within a state of Firstness is completely internal to an individual or to a group, and has no capacity to refer itself to an external reality for comparison. As an experience it is continuously perturbed, lacking the capacity to move itself into discrete instantiations or definitive measurements. If not picked up by more stable codal processes, 
the experience in this amorphous indeterminate state dissipates. We forget the data, the event, we lose the clarity of specificity and revert to subjective feelings or 'attributed interpretations'. Codifications in Firstness are unable to implement recording or descriptive systems, which are referential codes that stabilize the sensory-motor effervescent stimuli to provide the stability of memory. It should be clear that "the internal perspective is fundamentally distinction-free, i.e., no object can be distinguished from anything else" (Atmanspacher 1994:15). These amorphous experiences can be called 'sensate data' and are not to be confused with information or knowledge which are both more stable. It should be noted, however, that there is a functional usage of this type of semiosic codification within 'barn-storming sessions' for setting up a domain or institutional niche where more stable information processes can take place. Without the constraints of definitive measurements and a referential memory to stabilize the relation, sensate codification enables energy to explore its internal phase space in an expansive and arbitrary manner, in what is conceptually understood as an 'emotive' or 'imaginative' interaction. We can even compare this phase of codal relations with the tacit knowledge aspect of "sub-cellular level information processing" which is Abased on shapes rather than based on switches" (Hoffmeyer 2001:127).

Secondness is the mode of codification that acts as the "mutual action between two things regardless of any sort of third or medium, and in particular regardless of any law of action" (Peirce 1.322). Secondness refers to "such facts as another, relation, compulsion, effect, dependence, independence, negation, occurrence, reality, result" (Peirce 1.358). The key to mass codified within Secondness is that it exists as a singular unit, an observable, a 'knowable', something that is discrete in itself because its horizons or walls are actually acknowledged by that "mutual action between two things" as explicit limitations. Therefore "it is a real thing or fact which is a sign of its object by virtue of being connected with it as a matter of fact" (Peirce 4.447, my emphasis). The actual binding links with the environment stabilizes this type of codification, and we are now involved with 'information'. As Devlin points out, information is a substance "that can be acquired, stored, possessed either by an individual or jointly by a group, and transmitted from person to person or from group to group" (Devlin 1999:15). Information can be understood as discrete bits, as items of our experienced reality which are clearly differentiated and as such, we can assign a definite quantitative and qualitative description to their identity. Information is closed by virtue of those local constraints and relations. Information coded within Secondness is the basis of all our conscious experience - but - it is not the only reality. We do not operate only as 'billiard balls' bouncing against each other. With an obvious reference to classical physics, Peirce states that 
"there has been during the nineteenth century a decided leaning of scientific opinion to discredit any other sort of action in the external world than that of dynamical force; to understand a dynamical force to be a purely brute force with no element of inherent reasonableness in it, but merely to be the only force that scientific research could discover" [6.329]. There is another mode of codification that completes the basic triadic set.

Thirdness is a mode of mediate measurement that we have, as a result of the Cartesian and Newtonian focus on the proximate and indexical physical causality of discrete elements coded in Secondness ignored and indeed denied for years. However, "there is some essentially and irreducibly other element in the universe than pure dynamism or pure chance [and this is] the principle of the growth of principles, a tendency to generalization" (Peirce $6.322,6.585)$. Thirdness is a codification process that is operative both externally and internally, that transforms the diverse sensory-motor data of Firstness and the discrete atoms of Secondness into what Peirce referred to as cohesive diagrammes of communal knowledge. A diagramme is a figurative representation of parts and their relations as a whole, and as such "represents the entire collection, or aggregate, of possibilities of a certain description" (Peirce 4.351). It is a metaphor, an analogy, an abstraction, and "an abstraction is an ens rationis " (3.642) whose being, as Thirdness, works to glue, to bind, to relate, to establish relationships and connected interactions. It takes descriptive codes from the diverse instantiations of our internal and external experiences and develops a syncretic diagramme or Laws of relations of these descriptions such that subsequent local instantiations, within Firstness and Secondness, can emerge as versions or representations of these communal Laws. Thirdness is a "matter of law, and law is a matter of thought and meaning" (Peirce 1.345). Pure Thirdness, as interpretation by the mind, exists as a borderline or membrane phase operating as an interpretive compressing generalization. Paton calls such a process of developing this epistemological coherence 'glue' (Paton and Matsuno 1998) and that is a succinct image of its cohesive powers. It develops the normative habits, the 'quiescent memory' that underlies all specific interactions of a community.

This triadic set of codes can be summed up by stating that knowledge is a social or collective operation of generalization within the development of normative habits, while information is an irreversible, once-only instantiation of these habits as operative within the uniqueness of a local context and sensate experience is a 'fullness' of sensation without the distinct consciousness of such information. Knowledge only emerges via relating and exchanging different pieces of information, which themselves undergo changes in that process. Of central importance, is the suggestion that knowledge is embodied within collectives and communities and is an 
interpretive rather than reactive or reflective process. To return to the billiard ball analogy, knowledge is not the collection of balls but the rules of the game. And, although one can 'shoot pool' by oneself, to really 'play billiards' requires an opponent and thus a dialogical social context of several players (or at least one must play at being one's own opponent, but thereby imagine a social setting). One needs to ensure that there are people and processes that function as 'tranformers' or 'systems of mediation' who can broker the transformation of information out of one context, into a form of generalized knowledge, and then into a new form of information in a different context.

What we must consider, however, is that this dyadic architecture with its cuts between the external/internal and the physical/mental is not adversarial but indispensable, because each codal system provides different properties and enables a system, simple or complex, to invest its nature with a dynamic flexibility and thereby adapt itself to a variety of environments.

\section{ANALOG AND DIGITAL}

I have elsewhere defined the difference between information and knowledge as the difference between an analog and digital codification (Taborsky 2000, 2001; see also Hoffmeyer, 1996, 2001 and the analysis of code duality). Dretske outlines the difference between an analog and a digital encoding as "the difference between a continuous and a discrete representation" (1981:136). He clarifies this by stating that the digital Acarries the information...if and only if the signal carries no additional information" and the analog does "carry additional information...[such a] signal always carries more specific, more determinate, information" (1981:137). An analog codification is a 'situated' process, where data becomes information by virtue of its being located in recognisable contexts. It is meaningful due to those localised relations. A digital codification is compressed, decontextualized and encoded within the semiosic process of Thirdness. As such a general, non-local reference, it is able to insert its interpretative force within a wide variety of environments; an analog codification is tightly bound to its specific users and location. As Hoffmeyer states, a digital code allows "for impossible messages because there is no strict binding between the code itself and the message it carries"...Digital codes are codes for memory....Digital codes are eminent tools for the construction of meta-messages, i.e. messages necessary for interpreting other messages' (2001: 125-126).

Information, whether it be a voice mail or a document, will always carry data that is encoded both in analog and digital form. The analog codification, of Firstness and Secondness, sets up information that derives its meaning 
from its contextual, local, immediate relations. It is 'this' person speaking or writing, and 'this' information that is being experienced and discussed. The haecceity or localized links which establish 'thisness' sets up the essential definition of an analog code. The digital has abstracted the information from the local context and set up a more universal interpretation that is general enough that an analog instantiation can replicate that interpretation, as a 'this', but as related to another place and another time. As such, the digital codification permits a replication that can take information beyond the inflexibility of its local niche, beyond the confinement of its immediate horizons and users. It provides the means by which information can deviate from singular meanings, can evolve and adapt itself to new locations. The analog codification, again, permits information to operate relevant to 'this' particular environment and 'this' time. The digital codification permits information to expand its operations over space and over time and thus to become knowledge. Dretske outlines this transformation, as "a process by means of which information is delivered within a richer matrix of information " $(1981:$ 142) for the conversion of this sensate data to a representation or knowledge is "the conversion of information into...digital form that constitutes the essence of cognitive activity" (1981: 142). Then, using this stable digital code, life can adapt and evolve "through processes of genetic recombination...for creating endless chains of novelties" (Hoffmeyer 2001: 125).

Knowledge is embodied within a digital dynamic compressed code, Thirdness, which operates within the collective or community. Information is the analog individual and local articulation of that knowledge. Because knowledge exists at a higher order and scale, and is never completely formally articulated, it will continually evolve as information is passed between and articulated within the different contexts of the community or even, communities, of users. Even archived data must be reassessed and rearticulated to be meaningful or informative. Therefore, one cannot assume that there is a static stock of knowledge, much like that collection of billiard balls, which an organization possesses and which can be accessed by all workers at any given time. Knowledge is dynamic and abstract rather than discrete. As people meet new situations, knowledge will, in its nature as an evolving process of habitual norms, engage in establishing innovative links, which will be articulated in novel units of information, which will themselves be used to revise that knowledge-base. Knowledge is an emergent quality continuously reworked by those communities of information users. That is, "information is reflected upon and abstracted into knowledge collectively by a community of information users. In sociological terms, these communities are formed around an abstract process of knowledge generation, understood as a 'communal memory', which is 
brought together and actually engendered by the patterning of information flows related to the specific projects and services of that community" (Shields et al 2001: 25). Because knowledge cannot be reduced to singlevoiced articulations, i.e., information, knowledge itself cannot be directly managed. In short, while one can manage how information moves in an organization, one cannot manage knowledge. Specifically, information "is a precise descriptive measurement of association...data becomes information when it is assigned definite relational qualities (which may be qualitative, i.e., redness) or quantitative (an element of a set)" (Shields et al 2001:7), while knowledge as "an evolving synthetic or cultural consciousness" (Ibid:8) is a mediated process of generalization. These distinctions are not recognized within much of the language of knowledge management. That is why knowledge-management proponents often end up proposing information technology solutions to the problems within organizations and these solutions create yet more problems. This does not deny the relationship between information and knowledge; the two types of codification are entailed. "It is important here to stress the interdependence of the analog and digital as two equally necessary forms of referential activity" (Hoffmeyer 2001: 128) and we see that this differentiation enables the local to move into the communal and the communal to move into the local.

With these definitions of knowledge and information in mind, we move to consider their operations in more detail. We will describe a network of experience; this is not a map of a discernible reality, but is a way of conceptualizing the ways in which various actors (human and non-human, including databases, technologies, sets of rules and so on) come together and interact to construct both information and knowledge. For this, we must further explore semiotic actions within the external and the internal zones ${ }^{29}$.

\section{THE EXTERNAL ZONE}

This is the zone of our individual lived experiences and we are familiar with its Newtonian mechanics of action and reaction of units whose properties are distinct, separate and independent of the properties of other systems. This realm is the mainstay of codifications operating within Secondness. The properties of information in this zone operate in present time and space, and cannot be manipulated by a system encoded within a different spatial or temporal level, that is, within past or future time and space. This zone of experience denies information connections from the past

${ }^{29}$ This is the operative basis for totalitarianism, where the rules are detached from interaction with the current instantiations and are set up as a priori authority. 
or future as 'teleological', it denies information connections from the interpretive mind as 'psychic', it denies connections from the qualitative or uncertain as 'speculative'. The only force of interaction is proximate force, which is energy encoded in Secondness, the contextual direct links of local physical interaction.

This means that our experiences within this zone of interaction require a higher level description or a formal model to provide a cohesive overview that acts to reduce the isolation of these local analog interactions. The external zone requires an objective or detached observer, the hierarchical metalevel, which acts as a particular type of digital Thirdness (Taborsky 2001c), that sets up an inductive average of probabilities as a measuring device to provide a general overview of the discrete actions in this realm. Knowledge-about our reality in this zone is not inherent within the 'thingsin-themselves' but can be found at "the site of interactions of the system with an observer" (Farre 1998:683). Peirce calls this type of Thirdness a process operating by 'resemblance', a Thirdness of comparison, for "in portraiture, photographs mediate between the original and the likeness" (Peirce 1.367). A common example is the statistical average that also sets up a mediate 'comparison' that acts as a synthesizing overview. Knowledge in this zone is a features-extraction top-down managerial process, with a focus on the median average and an indifference to the marginal.

This view of the managerial requirements of the classical world is familiar in descriptions of animal life or of primitive man. In these scenarios, the preconscious random mode of isolate individualism, viewed as an original chaos, is understood to last until an authoritative modeling process emerges to develop constraints to authoritatively describe and plan agentenvironment interaction. The external zone has no "intrinsic powers of representation - no power that is not derived from us, their creators and users"(Dretske 1988: 53). This top-down managerial scenario of knowledge, by virtue of its authority, rejects peripheral interactions as noise or deviant. The classical model therefore has great difficulties with evolving new codes to generate new relations and new forms of information, for its basic analog or immediate relations are brute force and proximate causality, its only capacities of codification are additive or divisible and its memory refers only to the most common forms of behaviour. In addition, the top-down process, the digital memory, can itself become reified into an atemporal and aspatial inflexibility, a hegemonic structure of domination. The static model can then take operative precedence over reality, which becomes enslaved to the model. 


\section{THE INTERNAL ZONE}

In the internal zone of our experiences, information operates only in partially bound states of Firstness, with all the diversity of their codal properties superpositioned simultaneously and potentially available. The "asymmetrical, endo processes [are] more energetic than exo interactions" (Farre 1998:684). The system oscillates between all its potentials simultaneously. That is, information in the internal zone is highly volatile and contextual, its properties "must be conceived in a relational way as they depend on a changing material context" (Kampis 1994:103). This is the zone of our subjective sensate experiences whose validity is affirmed only by ourselves and the constant input of sensate experiences. Unlike the external perspective, internal codifications are not stabilized by being referenced to that managerial representational codal system of the inductive average, but develop a type of stability within an unconscious internal network of plastic relations.

The digital computations that develop knowledge or memory within the internal zone of experiences operate as a completely different type of Thirdness (Taborsky 2001c) and operate as a 'natural system of representation', which "have their own intrinsic indicator functions, functions that derive from the way the indicators are developed and used by the system of which they are a part" (Dretske 1988 62:italics in original). The system's codal relations do not depend on an external higher-being agential perspective, they do not depend on a statistical average of probabilities or indeed, on any external descriptive reality. These systems have, according to Dretske "what Haugeland (1981b) calls original intentionality and Searle (1980) calls intrinsic intentionality" (Dretske 1988: 65). Peirce calls this type of Thirdness 'accidental', for the bond is not a process of analytic thought but is instead a physical link, (its 'intrinsic' nature) where "a pin fasten two things together by sticking through one and also through the other" (Peirce 1.366). That is, the 'glue' that holds the sensate data, the internal experiences together, functions as revealed or essentialist truths. The long term rules which validate belief are defined within the system and do not refer to an objective model for validation. This view of truths as 'innate, universal and inviolate' can be found not only within religious ideologies but also within nineteenth century science which understood physics to function within inviolate Laws of Nature. Quantum mechanics ended that perspective. Sociologically, this is the realm of the isolationist self-referencing community whose beliefs and normative rules require no empirical proof. The internal semiosic codes cannot refer to an external reality, they cannot relate to a normative average; they are operative within the amorphousness of Firstness. What function does such an indeterminate semiosis provide? 
First- it promotes contact and interaction. The rejection of definite boundaries and the focus only on immediate experiences means that relations, connections, and 'togetherness' become increasingly important. We see this focus in management literature in praise of 'brown-bagging sessions', 'water-cooler bonds' and 'shared tasks'. Second, in contrast to the external zone's rigidity and emphasis on a crisp comparative description, the internal zone's digital laws, by virtue of their very accidental links, have a unique power of deviation from even their own norms. Dretske's comment is that these codes have "the power to misrepresent, the capacity to get things wrong, to say things that are not true" (1988:65) and we are well aware of the problems of an ingrown management community. However, if we establish links between the two realms, the external and the internal, and promote dialogue and interaction, then, the fact that the internal normative knowledge is developed solely within the system rather than with reference to any external reality, means that the system can itself, if pushed by external dialogue to a threshold limit, dissolve this knowledge and set up a new knowledge base. The internal zone, it seems, with its amorphousness and its volatile state of excitation, is also the site of innovation and novelty.

\section{THE NATURE OF ORGANISATIONAL COMPLEXITY}

We therefore have in our natural and social world an infrastructure that, by virtue of its ontological and epistemological cuts sets up two types of knowledge-processes. The external realm sets up an authoritative knowledge that is observer-driven and refers the particular bits of information, encoded in Secondness, to a judgmental normative template of habits codified in Thirdness. Its capacity for stability of operations and the expansion of common processes for dealing with the environment is unparalleled. This is the mantra of the factory system of production, the market-driven economy and the traditional institutional governance. However, the shortcomings of this externalist mode of cybernetic command and control are equally wellknown. Our modern industries and bureaucracies whether public or private have developed as a social form of cybernetic control. They operate within the view that knowledge is an additive collation of bits of information and that the ownership and generation of the full model of knowledge is a property of a privileged overview while information is the communication, by workers, only of the bits of manufactured information. The goal over many years has been to develop technology to move these bits farther and faster, within a fixed, mechanical or monological state between offices in the form of memos, directives, rules and so on. This stimulus-response external 
model sets up a mechanical input-output process in which each state of information is presented as an object which is itself unchanged by the knowledge process, but which, in a serial manner, leads to the next stage. In both theory and practice, this model creates serious problems. Operating only within the external realm, the traditional model ignores the subjective vitality of internal-to-the-group sensate data exchange, ignores the very real operating differences between analog and digital codification, ignores the inhibiting nature of an external digital memory that remembers only the inductive average, and rejects the dialogic transformation of information as it moves within a cycle of knowledge-information-knowledge, viewing such a dynamism as a degenerative or noise-producing process.. We see this structure, the traditional model of science and rationality, represented in numerous definitions of information and knowledge within the history of management literature.

The internal realm, on the other hand, sets up a niche-dependent communal network of emotive ties and local links that operate within a plenitude of sensate data encoded in the vagueness of Firstness. In this realm, information is viewed as flexible, amorphous, fleeting, subjective. The internal realm, because it rejects or simply does not see an ontological cut between itself and others, cannot achieve the cognitive distance to provide a self-referential descriptive outline, it cannot provide a detached overview of its actions. It cannot, in this sense, operate with any reliability, accountability, or predictive capacity. Bluntly put - an internal realm cannot analyse its past or plan its future. Its users can only 'feel' operative within their relations but cannot articulate those relations or the products of their discourse. A key danger in organisations that operate only within the internal realm will therefore be found within attempts to articulate an explicit cohesive modeling process. The members of this collective cannot use the external hierarchical superstructure because it requires an acceptance of scalar differentiation. Knowledge remains operative only within local constraints and subjective perspectives and thereby disables the development of a reflexive and analytic knowledge base and prevents expansion of the operating system beyond the local niche. The internal mode of operations focuses on its members as 'a community of citizens' and distrusts individual distinctions and individual goals. The internal realm as isolate, has always affirmed "the individual's bond to the community and stressed 'inheritance' and 'adherence"' (Benoist, in Antonio 2000:62). This sets up 'exclusionary monocultures' that reject communication and dialogue with other external groups and promotes cultural fragmentation and identity politics. That is, the internal realm rejects the reformation ideals of individual freedom and autonomy of information, which are properties of Secondness found in the external realm, and the concept of a universal knowledge of a common 
humanity, which are properties of an inductive Thirdness and it instead promotes the internal realm's unique codifications. The internal realm sets up information as bonded "attributes of a unitary, collective political subject" (Antonio 2000:64). That is, information must refer only to its collective relations; it cannot differentiate itself from this emotive magnetism. Its knowledge is equally communal and favours an "imagined community' where beliefs and values are completely cultural, specific to the group and unreferenced to any external reality, such that "knowledge and values are mere historical products of cultural groups, with no ultimate 'truth' or 'foundation' (Antonio 2000:67). Internal codification favours "pure continuity, ending communication, meaning, and sociality and foreclosing the basic democratic presupposition that people are capable of absorbing information, digesting it critically and employing it reasonably in citizenship, popular sovereignty, and social cooperation" (Antonio 2000:54). It is therefore, if monologic, as dangerous a realm as a monologic external realm. What does the internal realm provide? As previously stated, it promotes immediate acceptance of sensate data, a ready acceptance of any and all bits of information, and a rejection of normative standards - in other words - it provides the grounding for innovation, but if, and only if, it is linked with the external realm which can put that emergent information to the test of pragmatic viability.

These two realities, the external and internal zones, are antithetical to each other. How does one deal with contradictory worlds? Some have rejected the one in favour of the other. One level is real and the other a figment of our imagination $B$ and which is the real and which the fictive has been a matter of intense debate, whether between the symbolists and connectionists in artificial intelligence or the modernists and postmodernists in social theory. What if, rather than the one or the other of these realms, we postulate that our world necessarily requires both? How can we have one world operating with processes that are contradictory to each other? As Hoffmeyer insists, "it is important here to stress the interdependence of the analog and the digital as two equally necessary forms of referential activity....[and] had it not been for digital coding there would have been no stable access to the temporal world....had it not been for the analog codes there could have been no interaction with the world, no other-reference, and no preferences" (2001:128). The external and internal zones, and the formal and informal zones, exist because of these ontological and epistemological cuts. However, the existence of this asymmetry and the subsequent differentiation into 'zones of operation' enables the development of information 'bits' and knowledge 'relations' that together act to mediate these asymmetrical cuts. 
Work in complexity theory (Atmanspacher and Dalenoort 1994; Hofkirchner 1999, Greene, 2000) is showing how a unified, or more accurately an entangled, framework can operate. This analysis might have answers to such questions as - can global communication systems develop global knowledge that provides both expanding cohesive stability and futureoriented blueprints along with local contextually relevant information? Can functional or locally relevant informational processing systems emerge in spatially extended dynamical systems which have flexible central control, adaptive or flexible global accessible memory such that information can be both locally relevant and globally meaningful? The solution to the 'problem' of the two worlds may be an acceptance and promotion of both their differential separation along with their associative filiation. Together and only together, they provide the capacities for a generative and exploratory knowledge-system, creating closures within actual 'bits' of information, dissolving these closures and generating new closures, not haphazardly, but within the workings of an exploratory and evolutionary logic and pragmaticism. If we accept that "the emergence process is itself the result of the binding of two dynamical regimes, the endo-regime which is synergetic in nature, and the exo-regime of complex interactions" (Farre 1998: 685), then, we must both insist on and aggressively research the nature of this binding. What new understandings would be required to break with these two established views on manipulating information which see these two worlds as separate and non-dialogical? Instead, we advocate an infrastructure somewhat like a moebius strip, where the boundaries of these two realities or worlds are filiated, as in a double-helix, without denigrating the integrity of each string.

These definitions of information and knowledge stress the importance of recognising that there are two distinct ontological zones, the external and the internal, within which knowledge and information operate and that additionally, both information and knowledge are themselves epistemologically operative in two distinct codes. This intrinsic asymmetry sets up, not an isolation that is dealt with by a mechanical action-reaction process of, for example, an externalist domination over a subjective internal but a basic dynamism that is mediated by semiosic codifications.. Information is generated from the immediate experiences of a people intimately connected to the specific projects and local experienced realities of their environment. It is then moved to a higher level for analytic reflection where it is abstracted into collective general knowledge by a broader community of information users. What designates a collection of individuals as a community of information users, and delineates one community from another, is not an overriding cultural norm or unifying means of identity, as espoused within traditional tribal or identity politics (Antonio 2000), but the 
communal ability to take-up, communicate and adapt to specific, contextual and rapidly changing information processes in a different manner than another community. Knowledge, we recall, is the 'glue' that gathers and maintains communities (Paton and Matsuno 1998 ). What designates a community of knowledge-brokers is equally, the ability to extrapolate and generate discrete bits of information, adapted to the local environment, from this collective overview that is knowledge. Essentially, then, informationusers and generators are participant members of a collection of knowledgecommunities. What our information and knowledge systems should provide is an infrastructure that enables, first, membership in a diverse number of knowledge-communities, and second, a communication process that recognises the different natures of codification within internal and external zones of operation, i.e., within a group and with other groups, and recognises that information and knowledge are not only different from each other but are distinct within the internal and external zones.

\section{THE COMMUNITY OF INFORMATION USERS}

Analyses which treat knowledge and information as simple, static objects that are moved in a Shannon mechanical process from one site to another site obscure the durable cultures, structures, relations of power, and physical infrastructure and representations of information which actually shape the way in which information flows and how it is interpreted in an organisation. Information is contextual or situated, it is encoded within analog Secondness, it is unique and specific, i.e., it is the specific'know-how' needed to perform a particular task. Knowledge is decontextual, which is to say, it is capable of being distributed to a larger audience than the localised information; it is interpretive and general and is encoded within digital Thirdness. Therefore, knowledge never takes the form of a discrete unit, i.e., it can never be seen as 'information', as a specific fact. It operates within a dynamic process of integration within the community and comes to rest, so to speak, only when it is itself transformed and de-compressed, within the particularities of a local context, into information. As such, knowledge can never be fully represented or articulated within information, for it is 'larger than' and 'broader than' any local instantiation. Knowledge is abstracted from information by a community of users, compressed within the digital codes that permit its spatial and temporal expansion, and in turn, its general representations allow a person to adapt and apply information to a multitude of different situations. Knowledge, therefore, is an emergent property, it cannot be managed as a discrete entity and must be allowed to continually evolve dialogically. Therefore, the language of knowledge management $\mathrm{B}$ 
with its emphasis on sharing information only as moving discrete bits from site to site B obscures the fact that in practice one needs to focus, not on simply moving information (which can be a process based only around its nature as a discrete fact encoded as Secondness) and not simply on sharing information (which can be a process based around its nature as vague Firstness) but on transforming and interpreting that information to a new context. Rather than attempting to manage knowledge by reducing it to these collections of data-bits, which are then 'shipped' from culture to culture or office to office, and end up as that meaningless, nebulous Firstness, the focus should be on developing multiple and flexible communities of informationusers who are also enabled to act to generate dynamic knowledge bases. Thus, the development and operation of a dynamic and plastic dialogical world of multiple communities of information-users should be the focus of a new science of information systems.

Communicating information across barriers is not simply an act of translation, but of transformation. Information, to be pragmatically operative in a different locale, must be decontextualized from its former local relations, transformed into the general qualities of knowledge, and then, transformed yet again, by its new community of users, into information that is pragmatically operational in the new situation. As Peirce frequently pointed out, semiosis is an infinite process of interpretation. A diverse and ever-expanding community of users must develop processes that can perform this interpretive dynamics. How can it do this? First, the information in all these cultures or 'realms of discourse' must be accessible. The political and academic discipline barriers must be eliminated. We acknowledge that not all cognitive barriers can be eliminated, i.e., we are not advocating a homogenous or cave-like community of users but are advocating a scenario where all knowledge is open for reflexive critique. Second, the users must accept the necessity for on-going interpretation. Knowledge as a general communal memory must be understood as open and, in this sense, futureoriented. It cannot be assumed that it will be expressed in real life only as a mimetic copy in an authoritative form of discrete Secondness. Knowledge must be interpreted and transformed within each local context or office into a pragmatic information. These first two processes require a constant 'hum' of discourse, based on an understanding of the risks and consequences of this ongoing semiosis. The risk in this process of moving from an external-only zone is the establishment of an internal-only zone. How can this be prevented? By the insistence of objective accountability, by a focus on a pragmatic or future-oriented responsibility to the realities of the environment.

Information/ knowledge, in order to be useful, that is, to 'do work', must be pragmatic. Information/knowledge must be accountable to that which it 
interprets. The community of users will acknowledge that information and knowledge will of necessity have an intention to, at some time, reflect or properly interpret, our external reality. We are not advocating, in this outline of a flexible and interpretive semiosis, that these communities of users will produce a fictional discourse. Nor are we advocating that they arrive at a final discourse. Instead, a basic requirement of semiotics is that the signs that it generates must be pragmatically operational as reliable representations of that which they represent. Knowledge must be "really operative in nature" (Peirce 5.99), for genuine knowledge is viewed as a process that, itself, considers the effects it has on its surroundings. It is this form of pragmatic knowledge management which focuses on communities of information and knowledge-users, we conclude, that must be addressed by new information science initiatives.

\section{REFERENCES AND NOTES}

Antonio, R. (2000). 'After Postmodernism: Reactionary Tribalism". In: American Journal of Sociology. Vol. 106/2, 40-87.

Atmanspacher, H. (1994). 'Objectification as an Endo-Exo Transition'. In: Atmanspacher, H. and G. Dalenoort (Eds.). Inside Versus Outside . Berlin: Springer-Verlag. Pp. 15-32.

Atmanspacher, H. (1999). 'Cartesian Cut, Heisenberg Cut, and the Concept of Complexity'. In; The Quest for a Unified Theory of Information. Eds. W. Hofkirchner. Amsterdam: Gordon and Breach. Pp. 125-147.

Christiansen, P.V. (2000). 'Macro and Micro-Levels in Physics'. In: Andersen, P. Cl. Emmeche, Finnemann, N. and P. Christiansen. Eds. Downward Causation. Aarhus University Press. 51-63.

Davenport, T. and L. Prusak (1998). Working Knowledge. Cambridge, MA. Harvard University Press.

Devlin, K. (1999). Infosense: Turning Information into Knowledge. New York: W.H.Freeman

Dretske, F. (1981). Knowledge and the Flow of Information. Cambridge, MA.: MIT Press.

Dretske, F. (1988). Explaining Behavior. Cambridge, MA.: MIT Press.

Fenzl, N. (2000). 'Some Considerations about Interaction and Exchange of Information between Open and Self-Organizing Systems'. In: W. Hofkirchner (Ed). The Quest for a Unified Theory of Information'. Gordon and Breach. 189-195.

Farre, G. (1998). 'Information into Intelligence: An Interaction between two dynamical systems" In: Proceedings 1998 IEEE ISIC/CIRA/ISAS Joint Conference. Gaithersburg, MD., 683-688.

Greene, B. (2000). The Elegant Universe. New York: Vintage

Hoffmeyer, J. (1996). Signs of Meaning in the Universe. Bloomington, IN. Indiana UP

Hoffmeyer, J. (2001). 'Life and Reference'. In: BioSystems 60, 123-130.

Kampis, G. 1994 'Biological Evolution as a Process Viewed Internally'. In: Atmanspacher and Dalenoort. Pp. 85-110.

Matsuno, K. (1999). 'Resurrection of the Cartesian Physics'. In: The Quest for a Unified Theory of Information. Ed. W. Hofkirchner. Amsterdam: Gordon and Breach. Pp. 31-44. 
Matsuno, K. (1998). Dynamics of time and information in dynamic time'. In: BioSystems 46,57-71

Matsuno, K. (2001). 'Cohesive Interactions in Biomolecules and their organizations as energy consumers". Web site: http://bio.nagaokaut.ac.jp/ matsuno/preprints/LIVERPL3.htm

Matsuno, K and R. Paton (2000). 'Is there a biology of quantum information?' In: BioSystems $55,39-46$.

Paton, R. and K. Matsuno. (1998). 'Verbs, glue and categories in the cellular economy'. In: Holcombe, M. Paton, R. (Eds) Information Processing in Cells and Tissues'. New York: Plenum Press. 253-260.

Peirce, Ch. S. (1931-35). Collected Papers. Eds. Hartshorne, C. Weiss, P. and A. Burks. Cambridge, MA.: Harvard University Press. Citations are by volume and paragraph number.

Penrose, R. (1997). The Large, the Small and the Human Mind. With A. Shimony, N. Cartright, S. Hawking. Edited by M. Longair. Cambridge: Cambridge University Press.

Primas. H. (1993). 'The Cartesian Cut, the Heisenberg Cut and disentangled observers'. In: Symposia on the Foundation of Modern Physics: W. Pauli as a Philosopher. Eds. K. Laurikainen and C. Montonen. Singapore: World Scientific. Pp. 245-269.

Shields, R. and E. Taborsky. (2001). 'The New 'Knowledge Speak': The Implications of Contested Definitions of Knowledge and Information'. In: Australian Journal of Information Systems. May 2001. Vol. 8(2), 142-149.

Shields, R., S. Ilcan, D. O'Connor, E. Taborsky. (2001). 'The Impact of Knowledge-Based Economy on Work in the Public Service: The 'Virtual Organization' of Expertise and Knowledge. Forthcoming. Vancouver Strategic Research Conference.

Taborsky, E. (2002) 'The Natural Dynamics of Semiotic Realism'. Forthcoming. BioSemiotics Conference, Tartu, Estonia.

Taborsky, E. (2001c). 'Semiosis and Energy Transformation'. Forthcoming. CHAOS.

Taborsky, E. (2001b). 'The Internal and External Semiosic Properties of Reality". In: SEED.

Vol 1, 1. http://www.library.utoronto.ca/see

Taborsky, E. (2001a). 'The Emergence of Societies'. ECHO IV Proceedings. Forthcoming.

Taborsky, E. (2000). AThe Complex Information Process'. In: Entropy (2) 81-97.

Taborsky, E. (1999). Evolution of Consciousness. BioSystems 1999, 51, 153-168.

Taborsky, E. (1998). Architectonics of Semiosis; New York: St. Martin's Press. 